\title{
Pronunciation Teaching Practices in Canada
}

\author{
Judith A. Breitkreutz, Tracey M. Derwing, \\ and Marian J. Rossiter
}

We surveyed 67 ESL programs in Canada to determine to what extent pronunciation is taught and which resources are most often used. The survey also requested demographic information about the respondents and their ESL programs, classes and students, methods of teaching, and participants' attitudes. The respondents from approximately half the programs offer stand-alone pronunciation courses, and the balance reported that they integrate pronunciation teaching in their general ESL classes. The majority of respondents said that it was important to teach pronunciation at all levels, although few teachers have special training in this area. Resources preferred by the participants are discussed with regard to their emphases on segmental and suprasegmental aspects of pronunciation.

Par le biais d'un sondage, les auteurs ont étudié 67 programmes d'ALS au Canada dans le but d'évaluer dans quelle mesure on y enseigne la prononciation et de déterminer à quelles ressources on a le plus souvent recours. De plus, le sondage a permis de recueillir des données démographiques ainsi que de l'information sur les programmes d'ALS (cours, étudiants, méthodes d'enseignement et attitudes des participants). Les réponses indiquent qu'environ la moitié des programmes offrent des cours intégraux (autonomes) de prononciation; l'autre part consiste en des programmes dans lesquelles la prononciation est intégrée aux cours généraux de ALS. La majorité des répondants ont indiqué qu'il était important d'enseigner la prononciation à tous les niveaux, même si peu d'enseignants avaient la formation nécessaire pour le faire. L'article inclut une discussion des ressources que préferent les participants par rapport à l'importance qu'elles accordent aux aspects segmentaux et suprasegmentaux de la prononciation.

This study was initiated to determine to what extent the recent renewal in interest in pronunciation that is reflected in research and teacher resource books is also evident in classroom practice. The inception of a Pronunciation Special Interest Group in TESOL, the rise of "accent reduction" courses, and a variety of new student materials in both book and CD-ROM format point to the reemergence of pronunciation in the English as a second language (ESL) classroom. However, our own anecdotal experience suggested that 
many teachers are uncomfortable dealing with pronunciation, particularly given the multilingual nature of most ESL classes. Most of the instructors of our acquaintance have not had any specific training for the teaching of pronunciation; neither have they had much in the way of linguistic training in phonetics and phonology. Those who have had relevant coursework may have focused on basic skills (e.g., learning to recognize suprasegmental and segmental elements), but have not taken pronunciation-specific courses that focus on pedagogy (Murphy, 1997). These factors, in combination with the popularity of "pronunciation technique" workshops at ESL conferences, led us to wonder to what degree people actually incorporate pronunciation instruction in their classes.

The advent of the communicative approach to language teaching marked the decline of pronunciation instruction. This was due both to an increasing emphasis on input-based instruction and to the perception that pronunciation issues were related more to accuracy than to communication. Although the communicative approach represented an advance, it eventually became clear that there are some aspects of English that are not influenced by input alone. Schmidt (1995), in a comprehensive survey of psychological studies, has argued that second-language (L2) learners need to have their attention drawn to specific characteristics of a language if they are to make changes in their own productions. Although several studies have examined the role of instruction on well-defined grammatical structures (see Spada, 1997, for a review of the focus-on-form literature), only recently have there been studies that explore the effects of pronunciation teaching. Studies by Macdonald, Yule, and Powers (1994) and Derwing, Munro, and Wiebe (1997) suggested that pronunciation instruction can have an effect. Elliott (1997) and Derwing, Munro, and Wiebe (1998) conducted studies that indicated that segmental instruction may not transfer to spontaneous speech; the latter, however, found that suprasegmental instruction had a significant effect on listeners' impressions of the comprehensibility of spontaneously produced speech. Many teachers and teacher educators have recognized that some L2 students need direct assistance with pronunciation: for the last two decades, considerable numbers of people have come out of communicative classrooms who, despite large vocabularies and good comprehension skills, have difficulty making themselves understood.

Most current teacher references such as Avery and Ehrlich (1992), CelceMurcia, Brinton, and Goodwin (1996), Morley (1994), and Pennington (1996) are designed to provide ESL instructors with guidance in the teaching of pronunciation. Notably, these books take a departure from earlier texts in that they place more emphasis on suprasegmental aspects of speech (rhythm, intonation, stress), which are perceived to be more important from a communicative point of view, than on segmentals (individual consonants and vowels), which were the primary focus of earlier works. Many new resources 
intended for use in the classroom also reflect the increased emphasis on suprasegmentals (e.g., Beisbier, 1995; Hewings \& Goldstein, 1998), although others that purport to be comprehensive actually focus almost exclusively on segments (English Computerized Learning, 1996; Orion, 1997). As Jones (1997) indicated in a survey of commercial pronunciation materials, most still reflect a strong audiolingual focus despite efforts to include more communicative activities.

Although recent studies have shown that some adults have a remarkable facility to produce a second language learned after puberty without a detectable accent, such learners are few and far between (Bongaerts, van Summerin, Planken, \& Schils, 1997; Ioup, Boustagui, El Tigi, \& Moselle, 1994), and generally their first language is closely related to their second (Bongaerts, 1999). Extensive research has shown that the likelihood of acquiring a nativelike accent after puberty for most people is extremely slim (Flege, Frieda, \& Nozawa, 1997; Flege, Munro, \& MacKay, 1995; Scovel, 1988).

Although second-language users are often able to modify their pronunciation to the extent that native listeners find their productions significantly easier to understand (Derwing et al., 1997, 1998), total elimination of an accent is not a realistic goal. Nonetheless, given that comprehensibility can be enhanced, it is crucial to know which aspects of an accent cause the most problems for listeners. Anderson-Hsieh, Johnson, and Koehler (1992) conducted a study that suggested that prosodic factors are more important than segmentals. In a comparison of segmental versus suprasegmental approaches to pronunciation, Derwing et al. (1998) found that only suprasegmental teaching resulted in improved comprehensibility in spontaneous speech. Although segmental instruction was beneficial when students were asked to read sentences aloud, the effects did not appear to transfer to spontaneously produced utterances. The authors advocated an approach to pronunciation instruction in which segments are included but prosodic elements receive the major emphasis.

We were curious to know to what extent ESL programs incorporate pronunciation into their curricula and which approaches they favor. We also wished to know which materials are most popular across the country. For these reasons we designed the survey described below.

\section{Method}

\section{Participants}

Respondents were solicited from the population of teachers and program coordinators of Canadian ESL programs. Contacts were identified and selected from ESL program directories that represented the English-speaking provinces in Canada with the largest immigrant populations: Ontario, British Columbia, and Alberta. A number of instructors and program repre- 
sentatives attending the May 1999 TESL Canada conference also volunteered to participate in the survey; in this way we obtained some responses from Manitoba, Saskatchewan, and the Yukon. A total of 174 surveys were mailed, e-mailed, or faxed to ESL program representatives.

\section{Preparation of the Instrument}

We developed and twice revised the survey in the summer of 1999. The survey included demographic information about the respondents and their ESL programs, classes and students, methods of teaching, commercial resources, and attitudes. The instrument was piloted by instructors in two local ESL programs, and the comments and suggestions for clarification were used to formulate the final draft. Question types included multiple-choice and yes/no questions; the survey also included rating scales and an openended component. According to the pilot respondents, the survey took approximately 15 minutes to complete.

\section{Results}

Of the 174 surveys that were distributed, $67(39 \%)$ were returned. We asked the respondents to classify their program size as small ( 5 or fewer classes), medium (6-10 classes), or large (more than 10 classes). Forty-two percent of the returned surveys were from large programs, $25 \%$ from medium-sized programs, and 30\% from small programs (the remaining respondents did not complete this question). Respondents from $45 \%$ of the small programs, 35\% of the medium, and $46 \%$ of the large programs said that their programs offer pronunciation in stand-alone classes. We also asked participants to indicate to what extent they use language labs and computer labs for pronunciation practice. Reports that audio language labs are collecting dust everywhere may be somewhat exaggerated, but only $27 \%$ of the respondents indicated that students use the language lab (with tape-recorders) for pronunciation instruction. Interestingly, almost equal percentages of small, medium, and large programs reported using computer labs $(54 \%, 47 \%$, and $54 \%$ respectively).

Most of the program representatives felt that it is important to teach pronunciation to ESL learners at all levels: $85 \%$ thought it should be taught to beginners, $82 \%$ to intermediate level, and $70 \%$ felt that advanced learners should receive pronunciation instruction.

\section{Students}

Fifty-seven percent of respondents in the programs surveyed indicated that they have students registered in LINC programs, $36 \%$ offer TOEFL classes, $22 \%$ provide bridging courses, and $34 \%$ report offering other types of classes (e.g., business English, general ESL). The ESL providers indicated that the majority of their students $(78 \%)$ are permanent residents (immigrants, 
citizens, and refugee claimants), whereas $49 \%$ of programs have international students who will return to their home countries. Those students who are placed in stand-alone pronunciation classes are selected primarily through teacher recommendation (62\%), self-selection (55\%), proficiency level $(45 \%)$, and placement interview (45\%) (respondents could choose more than one answer).

\section{Attitudes}

We asked the respondents to rate their attitudes toward pronunciation using a scale, the anchors of which were strongly agree and strongly disagree. We collapsed the ends of the scale into agree (1-3) and disagree (5-7) categories. In general, the majority of the respondents' opinions appear to be in line with current research on the instruction of pronunciation (see Table 1). For example, the majority of respondents disagreed that the goal of a pronunciation program should be to eliminate a foreign accent. They also indicated that they believed instruction to be effective after the first few years in an

Table 1

Attitudes Toward Pronunciation

Statement

$\%$ Agree \% Unsure \% Disagree

The goal of a pronunciation program should be to

\% Agree \% Unsure \% Disagree

eliminate a foreign accent as much as possible.

Pronunciation instruction is only effective in the first 2-3 years after arrival.

There is an age-related limitation on the acquisition of native-like pronunciation.

Teaching pronunciation does not result in permanent changes.

Some individuals resist changing their pronunciation to maintain their L1 identity.

A heavy accent is a cause of discrimination.

Pronunciation instruction is most effective in a class with the same L1.

Pronunciation shouldn't be taught to lower levels.

Communicative practice is the best way to teach

pronunciation.

12

12

65

43

Drilling minimal pairs is the best way to teach

pronunciation.

Teaching pronunciation is boring.

Only native speakers should teach pronunciation.

The best person to teach pronunciation is a speech pathologist.
18

35

70

9

68

2

\section{9}

79

71

29

74

56

16

44

86

16

$16 \quad 25 \quad 59$

$8 \quad 9 \quad 83$

34

12

54

14

16

70 
English-speaking country. Two thirds of the respondents recognized that there is an age-related limitation on the acquisition of native-like pronunciation, yet three quarters believed that teaching pronunciation resulted in permanent changes.

When we asked respondents how important pronunciation instruction was for individuals of specific language backgrounds, $83 \%$ selected East Asian languages, including Japanese, Korean, Vietnamese, Cantonese, and Mandarin. The next largest grouping included Punjabi, Arabic, and Iranian. Over a quarter of the respondents identified Spanish as a language group most in need of pronunciation instruction.

\section{Focus of Instruction}

When respondents were asked whether they emphasized mainly prosodic features or individual sounds (segments) in their instruction, $89 \%$ stated that they teach a combination of the two. Nine percent reported an emphasis on prosody alone, whereas $2 \%$ taught segments only. Interestingly enough, however, an examination of the resources that are currently being used revealed that several of the most popular are purely segment-based (see Table 2). When asked which aspects of pronunciation were perceived to be most difficult to teach, $64 \%$ of respondents identified segments, $21 \%$ named prosodic features, and $15 \%$ provided both segmental and prosodic examples.

We asked respondents to indicate on the checklist provided what the best strategies are for L2 learners when faced with communication breakdown as a result of a pronunciation problem. The most popular response was to focus on troublesome sounds ( $85 \%)$, followed by repetition $(74 \%)$, and paraphrase $(57 \%)$. Speaking more slowly was chosen as the best strategy by $42 \%$ of respondents and speaking more loudly by $6 \%$.

Assessment of student progress in pronunciation ranges from perception to production tasks. Error detection, listening comprehension questions, and "written" tests are examples of the perception tasks used to assess improvement. Individual pre- and posttest recordings of spontaneous speech, oral reading passages, interviews, informal assessments, and commercial tests such as computer quizzes or the diagnostic test that appears in Clear Speech (Gilbert, 1993) were used in programs to evaluate students' progress in pronunciation.

\section{Teachers}

When respondents were asked whether most of their ESL instructors felt capable of teaching pronunciation, $76 \%$ answered affirmatively. The respondents also reported that a majority of ESL instructors in their programs do teach pronunciation $(73 \%)$, although only $30 \%$ have any pedagogical training in this area. The professional development opportunities for teachers in these programs are somewhat limited: $79 \%$ stated that their teachers could 
Table 2

Commercial Resources

\begin{tabular}{llcll}
\hline Texts/CD-ROMs & Author & $\begin{array}{c}\text { \% using now } \\
\text { now }\end{array}$ & $\begin{array}{c}\text { have used } \\
\text { used }\end{array}$ & $\begin{array}{l}\text { Primary } \\
\text { emphasis }\end{array}$ \\
\hline ELLIS Master Pronunciation* & CALI, Inc. & 60 & 11 & Segmental \\
Jazz Chants & Graham & 52 & 32 & Both \\
Clear Speech & Gilbert & 50 & 27 & Both \\
Pronunciation Pairs & Baker \& Goldstein & 44 & 19 & Segmental \\
Now Hear This & Foley & 32 & 25 & Suprasegmental \\
Pronunciation Power* & English Computerized & 29 & 11 & Segmental \\
& Learning & & & Both \\
Pronunciation Games & Hancock & 28 & 25 & Suprasegmental \\
Sounds Great & Beisbier & 22 & 16 & Suprasegmental \\
Well Said & Grant & 16 & 11 & Segmental \\
Pronunciation Contrasts in English & Nilsen \& Nilsen & 13 & 28 & Segmental . \\
Pronouncing American English & Orion & 11 & 17 & Both \\
Accurate English & Dauer & 11 & 5 & Suprasegmental \\
Pronunciation Plus & Hewings \& Goldstein & 8 & 10 & Suprasegmental \\
Speaking Solutions & Mathews & 6 & 9 & Segmental \\
Speech Works* & Blackmer \& Ferrier & 6 & 3 & \\
Manual of American English & & & & Segmental \\
Pronunciation & Prator \& Robinett & 5 & 14 & Both \\
Pronunciation Exercises for ESL & Esarey & 5 & 7 & Suprasegmental \\
Pronunciation in American English* & Hans & 3 & 3 & \\
\hline & & & &
\end{tabular}

${ }^{*} \mathrm{CD}-\mathrm{ROM}$

attend conference presentations; $69 \%$ offered in-house seminars; and finally, $12 \%$ could access university or college courses. Clearly, training options are available, but most tend to be single sessions, with few opportunities for in-depth study.

\section{Discussion}

According to the respondents, nearly three quarters of the programs have instructors who teach pronunciation. Although $46 \%$ of respondents indicated that their programs had stand-alone pronunciation courses, the openended comments suggested that in most cases the teachers included the pronunciation instruction in a conversation class or a general ESL course. What is not clear from the data is the degree to which teachers actually integrate pronunciation into the regular curriculum rather than devoting 10-30 minutes each class to specific pronunciation instruction. A number of comments suggested that there was a need for more integration of pronun- 
ciation in a communicative classroom, but there was a lack of knowledge about how to do so. Fully a quarter of the participants who responded to the open-ended question "Is there anything else you would like to mention about pronunciation instruction at your institution or in general?" stated that they feel that teachers lack sufficient training and training opportunities (recall that only $30 \%$ have any specific training). The following quotes exemplify this sentiment: "Training is minimal in too many TESL programs for teachers"; "In general, I believe instructors need more thorough training in this area. I certainly need more"; "We don't do enough of it because we don't know how"; "This is the one skill area that is neglected the most both in training courses and therefore in class"; "Generally, ESL teachers in this area are not well trained in teaching pronunciation, and usually avoid dealing with this subject." These results are reminiscent of those of Burgess and Spencer (2000), who found that there is a need for more pronunciation training for teachers in Britain; in particular, they advocated a stronger emphasis on pedagogical approaches rather than limiting instruction to the study of phonology.

The responses to the second research question, "Which resources are most often used?" indicate that many programs are using computer software, all of which is heavily segment-focused in nature, for pronunciation instruction. Some respondents expressed disappointment with the materials available to them, as noted here: "I'm quite surprised that the ELLIS CD-ROM doesn't have linking, syllable stress or sentence stress work on it (therefore covered in class)." "Material is not too great or interactive"; "lack of ... adequate materials"; "More clear, accessible, less technical 'communicative' resources needed." The most popular of the written materials were Jazz Chants (Graham, 1978) and Clear Speech (Gilbert, 1993), both of which have segmental and suprasegmental activities; these resources have stood the test of time. However, other texts that are outdated in the light of research findings are still used by a significant number of programs (e.g., Nilsen \& Nilsen, 1973). Moreover, neither date of publication nor title is a clear indicator of the nature of the content. Pronouncing American English: Sound, Stress and Intonation (Orion, 1997) is an example of a recent resource that places a heavy emphasis on segments.

In answer to the third research question, "What aspects of pronunciation are perceived to be most important?" an overwhelming majority of respondents believe that a combination of suprasegmental and segmental features is important. Interestingly, though, the same large majority felt that focusing on troublesome segments was the best strategy for L2 learners who had encountered a communication breakdown. 


\section{Conclusions}

It is evident from this study that there is a continuing need for curriculum and materials developers to incorporate pronunciation instruction into communicative contexts. It is especially important, given the high numbers of programs that regularly use computer laboratories as a component of pronunciation instruction, that software programs focus on more than segmental aspects of English. When we asked respondents to identify the most serious pronunciation problems experienced by their students, $45 \%$ said that they had difficulty with both suprasegmentals and segmentals, and another $9 \%$ with suprasegmentals only. Thus the CDs most often used by the respondents fail to address all the needs of students in $54 \%$ of the programs surveyed.

We were gratified to find that so many of the respondents favored a balanced approach to pronunciation instruction; however, the participants in this survey made it clear that TESL programs in Ontario, British Columbia, and Alberta at least should provide more offerings in current pedagogical approaches to pronunciation. The importance of pronunciation instruction for students who need it was made clear by those respondents who stressed the difficulties some of their learners had faced in the labor market because of their accents. Nearly everyone surveyed recognized that the goal of pronunciation teaching should not be to eliminate an accent, but to help people become more comprehensible. To help teachers achieve this goal, future research should focus on the identification of those aspects of learners' productions that are most likely to interfere with intelligibility.

We recognize the limitations of surveys. For example, the respondents who represented institutions may have had varying familiarity with the classes that offered pronunciation instruction. Similarly, we do not know the length of time that was devoted to pronunciation instruction in each. Despite the challenges to research based on survey responses, however, we feel that this study has succeeded in providing a snapshot of the current status of pronunciation instruction in Canadian ESL programs. The majority of respondents recognize that pronunciation matters, and almost half provide stand-alone pronunciation classes. Moreover, they recognize the need for more opportunities for inservice teacher training in this area.

\section{Acknowledgments}

We are very grateful to all the teachers and program directors who took the time to respond to this survey. Many thanks to Leanne Floden and Derrick Millard, who participated in the design of the survey, and to Kama Jamieson, who entered all the data. We appreciate the helpful comments of all the reviewers. This study was partly funded by an SSHRC grant awarded to the second author. 


\section{The Authors}

Judy Breitkreutz recently graduated from the TESL Master's program in the Department of Educational Psychology at the University of Alberta. She presently teaches at Grant MacEwan College.

Tracey Derwing is a professor in the TESL program at the University of Alberta. She conducts research in the areas of native speaker-nonnative speaker communication and refugee studies.

Marian Rossiter recently completed her doctorate at the University of Alberta. She has done extensive research on language learning strategies.

\section{References}

Anderson-Hsieh, J., Johnson, R., \& Koehler, K. (1992). The relationship between native speaker judgments of non-native pronunciation and deviance in segmentals, prosody, and syllable structure. Language Learning, 42, 529-555.

Avery, P., \& Ehrlich, S. (Eds.). (1992). Teaching American English pronunciation. Oxford, UK: Oxford University Press.

Baker, A., \& Goldstein, S. (1989). Pronunciation pairs: An introductory course for students of English. Cambridge, UK: Cambridge University Press.

Beisbier, B. (1995). Sounds great: Intermediate pronunciation and speaking. Boston, MA: Heinle and Heinle.

Bongaerts, T. (1999). Nativelikeness of pronunciation in naturalistic post-critical period second language acquisition. Paper presented at AILA 99, Tokyo.

Bongaerts, T., van Summerin, C., Planken, B., \& Schils, E. (1997). Age and ultimate attainment in the pronunciation of a foreign language. Studies in Second Language Acquisition, 19, 447-465.

Burgess, J., \& Spencer, S. (2000). Phonology and pronunciation in integrated language teaching and teacher education. System, 28, 191-215.

Celce-Murcia, M., Brinton, D.M., \& Goodwin, J.M. (1996). Teaching pronunciation: A reference for teachers of English to speakers of other languages. Cambridge, UK: Cambridge University Press.

Derwing, T.M., Munro, M.J., \& Wiebe, G.E. (1997). Pronunciation instruction for "fossilized" learners: Can it help? Applied Language Learning, 8, 217-35.

Derwing, T.M., Munro, M.J., \& Wiebe, G.E. (1998). Evidence in favor of a broad framework for pronunciation instruction. Language Learning, 48, 393-410.

Elliott, A.R. (1997). On the teaching and acquisition of pronunciation within a communicative approach. Hispania, 80, 95-108.

English Computerized Learning, Inc. (1996). Pronunciation power. Edmonton, AB: Author.

Flege, J.E., Frieda, E.M., \& Nozawa, T. (1997). Amount of native-language (L1) use affects the pronunciation of an L2. Journal of Phonetics, 25, 169-186.

Flege, J.E., Munro, M.J., \& MacKay, I.R.A. (1995). Factors affecting degree of perceived foreign accent in a second language. Journal of the Acoustical Society of America, 97,370-389.

Gilbert, J.B. (1993). Clear speech: Pronunciation and listening comprehension in North American English. Student's book (2nd ed.). New York: Cambridge University Press.

Graham, C. (1978). Jazz chants: Rhythms of American English for students of English as a second language. New York: Oxford University Press.

Hewings, M., \& Goldstein, S. (1998). Pronunciation plus: Practice through interaction. Cambridge, UK: Cambridge University Press.

Ioup, G., Boustagui, E., El Tigi, M., \& Moselle, M. (1994). Reexamining the critical period hypothesis: A case study of successful adult SLA in a naturalistic environment. Studies in Second Language Acquisition, 16, 73-98. 
Jones, R. (1997) Beyond "listen and repeat": Pronunciation teaching materials and theories of second language acquisition. System, 25, 103-112.

Macdonald, D., Yule, G., \& Powers, M. (1994). Attempts to improve L2 pronunciation: The variable effects of different types of instruction. Language Learning, 44, 75-100.

Morley, J. (Ed.). (1994). Pronunciation pedagogy and theory: New views, new dimensions. Alexandria, VA: TESOL.

Murphy, J.M. (1997). Phonology courses offered by MATESOL programs in the US. TESOL Quarterly, 31, 741-764.

Nilsen, D.L.F., \& Nilsen, A.P. (1973). Pronunciation contrasts in English. New York: Regents.

Orion, G.F. (1997). Pronouncing American English: Sounds, stress, and intonation. Pacific Grove, CA: Heinle \& Heinle.

Pennington, M.C. (1996). Phonology in English language teaching: An international approach. London: Longman.

Schmidt, R. (1995). Consciousness and foreign language learning: A tutorial on the role of attention and awareness in learning. In R. Schmidt (Ed.), Attention and awureness in foreign language learning (pp. 1-63). Honolulu, HI: University of Hawaii Press.

Scovel, T. (1989). A time to speak: A psycholinguistic inquiry into the critical period for human speech. Cambridge, UK: Newbury House.

Spada, N. (1997). Form-focussed instruction and second language acquisition: A review of classroom and laboratory research. Language Teaching, 29, 1-15. 